\title{
Influence of metallic porous microlayer on pressure drop and heat transfer of stainless steel plate heat exchanger
}

\author{
Jan WAJS ${ }^{1,2, *}$, Dariusz MIKIELEWICZ ${ }^{1,2}$ \\ * Corresponding author: Email: janwajs@pg.gda.pl \\ 1: Department of Energy and Industrial Apparatus, Gdansk University of Technology, Poland \\ 2: The Szewalski Institute of Fluid-Flow Machinery, Polish Academy of Sciences, Poland
}

\begin{abstract}
The experimental analysis of passive heat transfer intensification in the case of plate heat exchanger has been carried out. On the heat transfer surface of heat exchanger the metallic porous layer was created. The experiment was accomplished in two stages. In the first stage the commercial stainless steel gasketed plate heat exchanger was investigated, while in the second one - the identical heat exchanger but with the modified heat transfer surface. The direct comparison of thermal and flow characteristics between both devices was possible due to the assurance of equivalent conditions during the experiment. Equivalent conditions mean the same volumetric flow rates and the same media temperatures at the inlet of heat exchangers in the corresponding measurement series. Experimental data were collected for the single-phase convective heat transfer in the water-ethanol configuration. The heat transfer coefficients were determined using the Wilson method.
\end{abstract}

Keywords: Porous microlyaer, Heat transfer intensification, Plate heat exchanger

\section{Introduction}

Efficient heat production and distribution is very important from the economical and natural resources depletion points of view. Therefore an extensive research and development efforts have been undertaken in the area of heat transfer intensification over the past couple of decades. They refer to the single-phase convection and also to the boiling/condensation conditions. Nowadays we can observe a tendency to miniaturization in every field of life, but especially in technical applications. At the same time, in the area of energy technology very important are the high heat fluxes transfer problems. This is the reason why these new challenges require high efficiency of system components, especially highly efficient and small capacity heat exchangers. It is known that in the recuperators the heat transfer coefficients on both sides of partition are the most significant and they determined their capacity. Because the overall heat transfer coefficient depends on the lowest value among the heat transfer coefficients, a special care should be given to the heat transfer conditions on the "weaker" side in the heat exchanger.

Plate heat exchangers have been widely used in power engineering, chemical processes and many other industrial applications due to their good effectiveness and compactness. Nevertheless there are still investigations going toward even more efficient and smaller size ones. They are going to be obtained by the heat transfer intensification and this new kind of plate heat exchangers could be prospectively applied for example in the heat recovery systems.

General overview of heat transfer (in the flow passages) augmentation by passive methods can be found in literature (Gupta and Uniyal, 2012), while Stone (1996) concentrated on the heat transfer intensification in compact heat exchangers. He presented the methods of augmentation assessment by various parameters, followed by overview of heat exchangers geometries including many kinds of fins, wavy and corrugated channels, etc. Research connected with corrugated plate heat exchangers are going in many directions. It may be 
concentrated on the heat transfer coefficient and formulation of heat transfer correlation (Khan et al., 2010) on the pressure drop and friction factor correlation (Arseneyeva et al., 2011) or both of them (Dovic et al., 2009).

Recently a large number of investigations on plate heat exchangers were reported in the professional literature. Unfortunately, rather limited data for units with high performance microsizes, enhancement structures were available. Among them could be found works by Furberg et al. (2009). Their aim was to enhance pool boiling heat transfer caused by $\mathrm{R} 134 \mathrm{a}$ with over one order of magnitude higher values in comparison with a plain machined copper surface. They presented an experimental study of the plate heat exchanger evaporator performance with and without this novel enhancement structure applied to the refrigerant channel.

Müller-Steinhagen (2008) described and analyzed a vacuum plasma sprayed $250 \mu \mathrm{m}$ thick layer of spherically shaped Inconel 625 particles on to a plate and frame heat exchanger surface. The particles had a diameter of $105-170 \mu \mathrm{m}$ and enhanced the boiling heat transfer coefficient of R134a by up to $100 \%$.

The experiences connected with the passive heat transfer enhancement in the case of plate heat exchangers were also presented by Wajs and Mikielewicz (2014). These authors proposed a new technique of increasing the surface roughness, through its abrasive blasting with the utilization of glass micro-beads. Granulation of the beads was approximately $300-400 \mu \mathrm{m}$. Such technique is relatively cheap and still produces the enhancement effect. They conducted the series of experiments comparing the commercially available heat exchanger with the modified surface heat exchanger. The thermal analysis showed that overall heat transfer coefficient for the highest value of hot water mass flux was higher for the commercial heat exchanger than for the modified one. On the other hand, for the lowest value of hot water mass flux the opposite situation was found. Within these limits (the highest and the lowest values of mass flux) there was the transient range, as named by the authors, where the overall heat transfer coefficient for some values of heat flux was higher for the commercial heat exchanger, for the other - higher for the modified heat exchanger. This tendency was observed by the authors for the first time but was also found for the different inlet temperature conditions of heat exchangers.

In this paper the experimental analysis of passive heat transfer intensification in the case of model plate heat exchanger has been presented. The passive intensification was obtained by a modification of heat transfer surface, which was this time covered by a metallic porous microlayer. As previously, the experiment was done in two stages, for two heat exchangers, that is the commercial stainless steel gasketed one and the identical heat exchanger but with the modified heat transfer surface. Experimental data were collected for the single-phase convective heat transfer in the water-water and water-ethanol system. The heat transfer coefficients were determined using the Wilson method.

\section{Plate heat exchanger (PHE)}

The model of twisted plate heat exchanger offered at the domestic/world market was the subject of presented investigations. In this kind of heat exchanger the heat is transferred in one pass. The model was made of 316 stainless steel according to AISI standard and consisted of three plates, whose thickness was $0.5 \mathrm{~mm}$. The surface roughness of working plate was equal to $0.46 \mu \mathrm{m}$ (parameter $R_{a}$ ) and $3.36 \mu \mathrm{m}$ (parameter $R_{z}$ ), respectively. The total length of the heat exchanger was $450 \mathrm{~mm}$, while the overall heat transfer area was equal to $0.039 \mathrm{~m}^{2}$. The distance between the plates was kept constant and the EPDM seal was fixed in the "hang on" system. Permissible working pressure was equal to $1.6 \mathrm{MPa}$. The schematic view of heat exchanger plate is presented in Fig. 1.

To meet the needs of experiment the second stage the porous layer was created on the heat transfer surface. The special metal finishing was applied to increase the surface roughness. As an abrasive agent the broken 
alundum of $500 \mu \mathrm{m}$ average grain size was used. The alundum grains were carried by the stream of compressed air under the pressure of $0.6 \mathrm{MPa}$. This metal finishing increased the surface roughness about three times in comparison with the original plate.
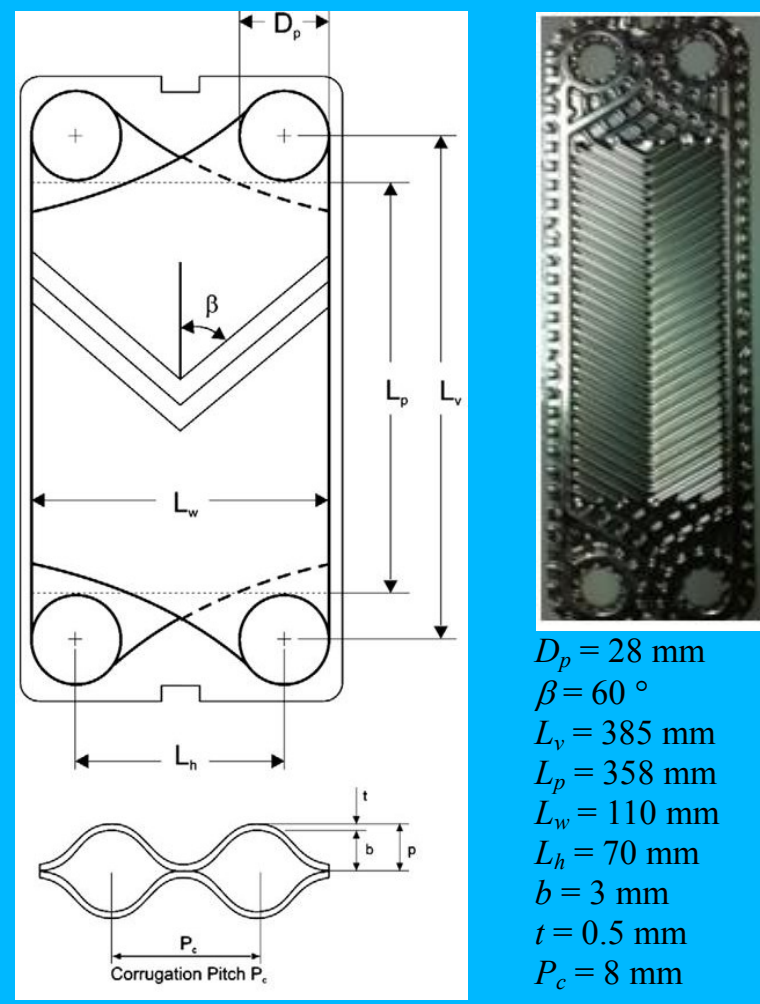

Fig. 1. Schematic of heat exchanger plate with characteristic parameters

\section{Experiment}

The second test stand enabled the heat transfer tests by convection between the hot water and ethanol, Fig. 2. Water was the heating medium, while ethanol - the coolant.

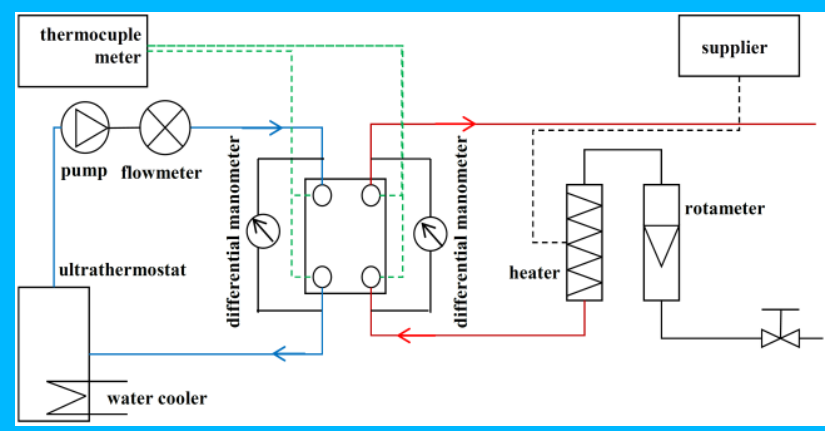

Fig. 2. Scheme of experimental facility

The stream of water was first directed to the rotameter and then to the electrical heater to obtain required parameters at the inlet to heat exchanger. The heater was controlled by an autotransformer, which allowed smooth adjustment of heater power and then the precise water temperature settings.

The ethanol was circulating in a closed system equipped with thermostatic bath, which heated it to a certain level before entering the heat exchanger. For the needs of experiment an additional heat exchanger, supplied with the tap water (cold) was provided to the thermostatic bath. Because of that the thermal energy gained by the ethanol could be withdrawn from it, what assured the stationary state of the analysis.

During experiments the mass flow rate of hot water was varied in the range from 50 to $125 \mathrm{dm}^{3} / \mathrm{h}$, while the ethanol mass flow rate was varied in the range from 35 to $160 \mathrm{dm}^{3} / \mathrm{h}$. Temperature of the hot water supplying the heat exchanger was 80 and $60^{\circ} \mathrm{C}$, whereas the ethanol temperature was in each measurements' series equal to $30 \pm 0.5^{\circ} \mathrm{C}$.

In experiment the pressure drop was measured by differential pressure transducer (Huba Control sensor) with accuracy of $1 \%$ of the full scale. Thermocouples of J-type were used to measure temperature in four locations i.e. at the inlet and outlet of heat exchanger cold side and at the inlet and outlet of heat exchanger hot side.

During experiments the following parameters were measured: the hot fluid temperature at the inlet $\left(T_{h-i n}\right)$ and at the outlet $\left(T_{\text {h-out }}\right)$ of heat exchanger, the cold fluid temperature at the inlet $\left(T_{c-i n}\right)$ and at the outlet $\left(T_{c-o u t}\right)$ of heat exchanger, the pressure drops connected with the fluid flow $\left(\Delta P_{\exp }\right)$, the volumetric flow rate of hot water and the volumetric/mass flow rate of working fluids. On the basis of measurement results the heat flux $(q)$, the Logarithmic Mean Temperature Difference (LMTD) in the heat exchanger and the overall heat transfer coefficient $\left(U_{0}\right)$ were calculated. The overall heat transfer coefficient was determined with the aid of the Peclet law based on the heat transfer area equal to $0.039 \mathrm{~m}^{2}$ and average value of the heat rate transferred through the wall in a given measurement series. 


\section{Heat transfer coefficient}

The experimental investigations of heat exchangers require determination of mean heat transfer coefficients on both sides of the wall separating exchanging heat fluids. Usually that requires installation of thermocouples for measurements of wall temperature separating two fluids. If the heat exchanger has a complex surface geometry then accurate measurement of the mean surface temperature faces significant difficulties for example in the course of disassembling installation a large number of thermocouples must be attached and subsequently everything must be reassembled again. Such difficulties can be alleviated if the Wilson's method (Wilson, 1915) is applied or the improved versions of that method. The method is very simple and can be applied to the analysis of different types of heat exchangers (Fernandez-Seara et al., 2007). A simple and efficient version of the Wilson method, a version similar to the original one was applied in the course of determination of heat transfer coefficient. The original Wilson method, as well as its modifications, require only determination of the overall thermal resistance in the heat exchanger. From the Wilson's method an accurate energy balance, based on measurement of flow rates of fluids exchanging heat and their mean temperatures at inlet and outlet of the heat exchanger are obtained.

The thermal balance of heat exchanger can be presented in the form:

$$
\dot{Q}=U_{0} \cdot L M T D \cdot A=\dot{m}_{h} \Delta h_{h}=\dot{m}_{c} \Delta h_{c}
$$

where: LMTD - logarithmic mean temperature difference, $A$ - heat transfer surface, whereas overall heat transfer coefficient can be described as:

$$
U_{0}=\left(\frac{1}{\alpha_{h}}+\frac{\delta}{\lambda}+\frac{1}{\alpha_{c}}\right)^{-1}
$$

where: $\alpha_{h}$ and $\alpha_{c}$ are heat transfer coefficients for respective mass flow rates; $\delta$ is a thickness of a wall separating two fluids, whereas $\lambda$ its thermal conductivity.
The mean wall temperature can be determined from a relation:

$$
L M T D=\frac{\left(T_{h_{-} \text {in }}-T_{c_{-} \text {out }}\right)-\left(T_{h_{-} \text {out }}-T_{c_{-} \text {in }}\right)}{\ln \frac{\left(T_{h_{-} \text {in }}-T_{c_{-} \text {out }}\right)}{\left(T_{h_{-} \text {out }}-T_{c_{-} \text {in }}\right)}}
$$

That is especially important in the case of finned tubes where determination of a mean value of wall temperature is difficult basing on local measurements.

Assuming that heat transfer is primarily governed by flow velocities of both fluids, the simple relations for heat transfer coefficient in function of fluid velocity can be written:

for $\quad \dot{m}_{c}=$ const and $\dot{m}_{h}=$ var there is:

$$
\alpha_{c}=\text { const }, \alpha_{h}=C_{h} w_{h}^{n}
$$

for $\dot{m}_{h}=$ const and $\dot{m}_{c}=$ var there is:

$$
\alpha_{h}=\operatorname{con} s, \alpha_{c}=C_{c} w_{c}^{n}
$$

where $w_{h}$ and $w_{c}$ are respective flow velocities; $n$ is the coefficient depending on the character of heat transfer, for example in case of turbulent flow inside tubes $n=0.8$, whereas in case of a laminar one, $n=0.5$.

For heating medium following relation can be formulated:

$$
\frac{1}{U_{0}}=\left(\frac{1}{\alpha_{c}}+\frac{\delta}{\lambda}\right)+C_{h} w_{h}^{-n}
$$

or: $\quad \frac{1}{U_{0}}=C_{3}+C_{h} w_{h}^{-n}$

where: $\quad C_{3}=\frac{1}{\alpha_{c}}+\frac{\delta}{\lambda}$

for a series where $\dot{m}_{c}=$ const. Assuming new variables, i.e. $x=w_{h}^{-n}$ and $y=1 / U_{0} \quad$ a linear relation is obtained:

$$
y=C_{3}+C_{h} x
$$

For cooling side analogical relations can be derived.

The heat transfer coefficient calculations by Wilson's method were conducted for the plate thickness of $0.5 \mathrm{~mm}$. The plate material (the stainless steel) has the thermal conductivity $\lambda$ equal to $15 \mathrm{~W} /(\mathrm{mK})$. For 
example, for the coolant (ethanol) the straight line described by formula (9) was plotted in Fig. 3, where $C_{h}=33 \times 10^{-6}$ and $C_{3}=25 \times 10^{-5}$ (modified) and $C_{h}=26 \times 10^{-6}$ and $C_{3}=30.6 \times 10^{-5}$ (commercial).

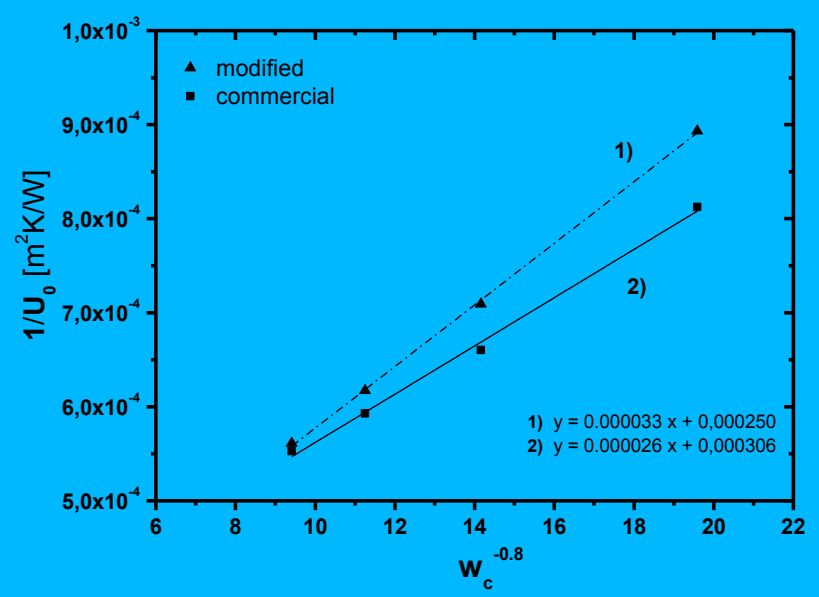

Fig. 3. Experimental points and linear regression, $\dot{V}_{C}=125 \mathrm{dm}^{3} / \mathrm{h}$

The heat transfer coefficient values obtained in hot and cold passes are shown below. Their values versus Reynolds number for one chevron channel (as usually presented in the papers) is presented in Fig. 4 and Fig. 5. During tests the inlet temperature of hot water and ethanol (cooling fluid) was kept constant (see legend of mentioned figures).

The Reynolds number was calculated with application of the formula:

$$
\operatorname{Re}_{1 C h}=\frac{G_{1 C h} D_{H}}{\mu}
$$

where hydraulic diameter, $D_{H}$, is usually taken as double corrugated depth $\left(D_{H}=2 b\right)$. The viscosity of both fluids was taken from Refprop software for average temperature of hot passage $\left(T_{h-i n}+T_{h-o u t}\right) / 2$ and cold passage $\left(T_{c \text {-in }}+T_{\text {c-out }}\right) / 2$ in the heat exchanger, respectively. The one channel mass flux, $G_{l C h}$, is defined as:

$$
G_{1 C h}=\frac{m}{b L_{w}}
$$

In Eq. (11) $\dot{m}$ is the mass flow rate, $b$ is the plate corrugation depth, whereas $L_{w}$ is the plate width.

The heat transfer coefficient on the ethanol (cold) side took higher values for the modified heat exchanger in all studied cases, but the water (hot) side it was higher for the commercial one.

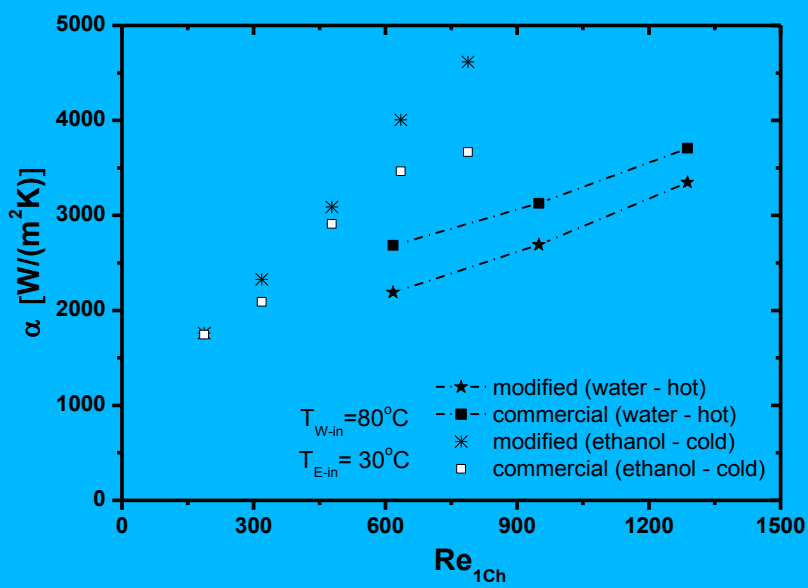

Fig. 4. Heat transfer coefficient versus Reynolds number; $T_{h-i n}=80^{\circ} \mathrm{C}$

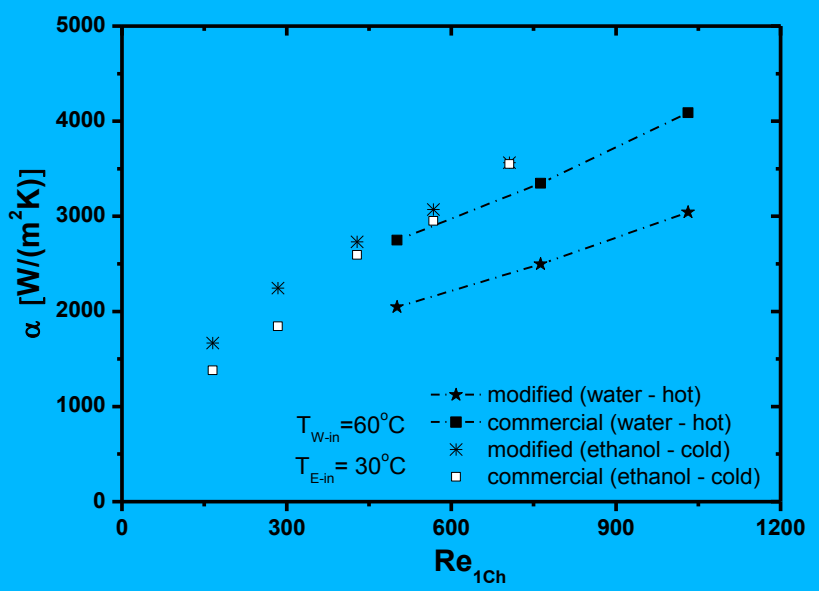

Fig. 5. Heat transfer coefficient versus Reynolds number; $T_{h-i n}=60^{\circ} \mathrm{C}$

\section{Thermal characteristics}

The exemplary comparison of studied heat exchangers' thermal characteristics are shown below. The direct comparison of thermal and flow characteristics between both devices was possible due to the assurance of equivalent conditions during the experiment. Equivalent conditions mean the same volumetric flow rates and the same media temperatures at the inlet of heat exchangers in the corresponding measurements' series.

The effect of the water mass flux and imposed heat flux density on the overall heat transfer coefficient in the studied plate heat exchangers are presented in Fig. 6 and Fig. 7. The presented below particular graphs were 
constructed at the following conditions: temperature of hot water at the heat exchanger inlet was kept at $60^{\circ} \mathrm{C}$, temperature of ethanol at the heat exchanger's inlet was $30^{\circ} \mathrm{C}$, the mass flux of hot water $\left(G_{h}\right)$ was constant.

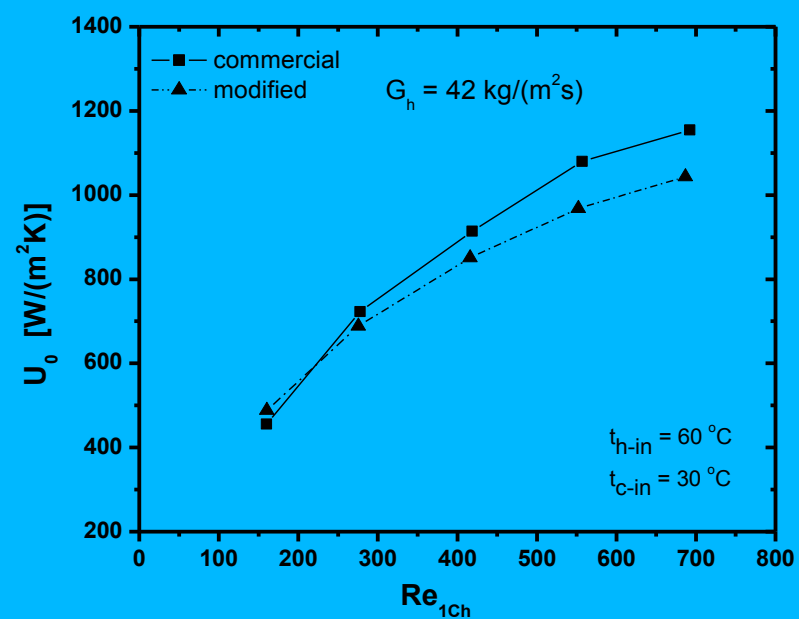

Fig. 6. Overall heat transfer coefficient versus Reynolds number, $G_{h}=42 \mathrm{~kg} \mathrm{~m}^{-2} \mathrm{~s}^{-1}$

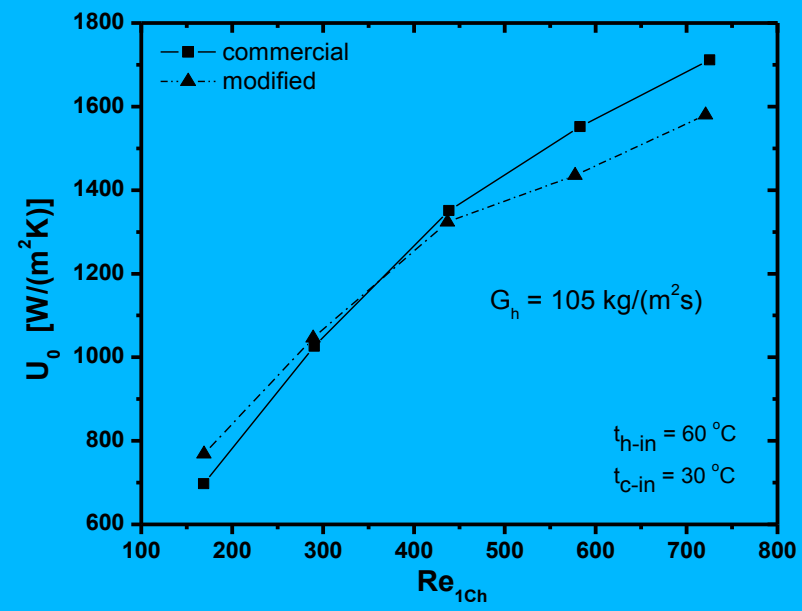

Fig. 7. Overall heat transfer coefficient versus

Reynolds number, $G_{h}=105 \mathrm{~kg} \mathrm{~m}^{-2} \mathrm{~s}^{-1}$

The results in Figures 6 and 7 can be divided into two parts: namely the low Reynolds number region (up to 300) and the higher Reynolds number region (over 300). This division is coming from the fact, that in the low Reynolds number region the overall heat transfer coefficient is higher for the case of modified heat exchanger than for the commercial one by about $15 \%$. On the other hand, in the higher Reynolds number region the commercial heat exchanger is characterized by the higher values of overall heat transfer coefficient (by about 6\%) than the modified one. Such tendency was observed for both cases of mass flux, equal to 42 and $105 \mathrm{~kg} \mathrm{~m}^{-2} \mathrm{~s}^{-1}$. Similar results were obtained for measurements' series, when temperature of hot water at the heat exchanger's inlet was equal to $80^{\circ} \mathrm{C}$ and temperature of ethanol at the heat exchanger's inlet was equal to $30^{\circ} \mathrm{C}$.

\section{Hydraulic characteristics}

Generally, the total pressure drop $\left(\Delta P_{\exp }\right)$ consists of four factors, namely the frictional term $\left(\Delta P_{f}\right)$, elevation term $\left(\Delta P_{g}\right)$, pressure losses at the test section inlet and outlet ports $\left(\Delta P_{p}\right)$, and the acceleration term $\left(\Delta P_{a}\right)$. The latter term is included in the analysis only if the phase change of particular fluid would be observed. Therefore in the case of reported study, the acceleration term was omitted because there was no phase change at this stage of experiment. The gravitational component was not taken into account due to the horizontal position of heat exchangers. To evaluate the friction factor associated with the water flows, the frictional pressure drop $\left(\Delta P_{f}\right)$ was calculated by subtracting the pressure losses at the ports of heat exchanger from the measured total pressure drop:

$$
\Delta P_{f}=\Delta P_{\exp }-\Delta P_{p}
$$

The pressure drop at the inlet and outlet ports of heat exchanger was empirically suggested by Shah and Sekulic (2003). This is approximately 1.5 times the head due to the flow expansion at the inlet:

$$
\Delta P_{p} \approx 1.5\left(\frac{G_{p}^{2}}{2 \rho}\right)
$$

where $\rho$ is the density of fluid, while the mass flux inside the port, $G_{p}$, is defined as:

$$
G_{p}=\frac{4 \dot{m}}{\pi D_{p}^{2}}
$$

In Eq. (14) $D_{p}$ is the port diameter.

The friction factor is described by formula:

$$
f=\frac{\Delta P_{f} D_{H} \rho}{2{G_{1 C h}}^{2} L_{p}}
$$

where $L_{p}$ is the active length of heat exchanger. 
The flow characteristics are presented in Fig. 8 (for water side) and Fig. 9 (for ethanol side).

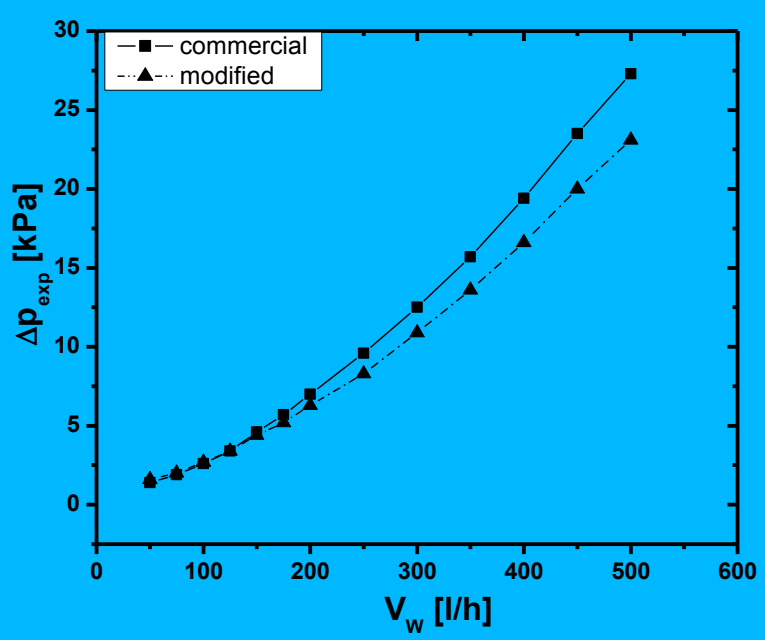

Fig. 8. Flow characteristics for water

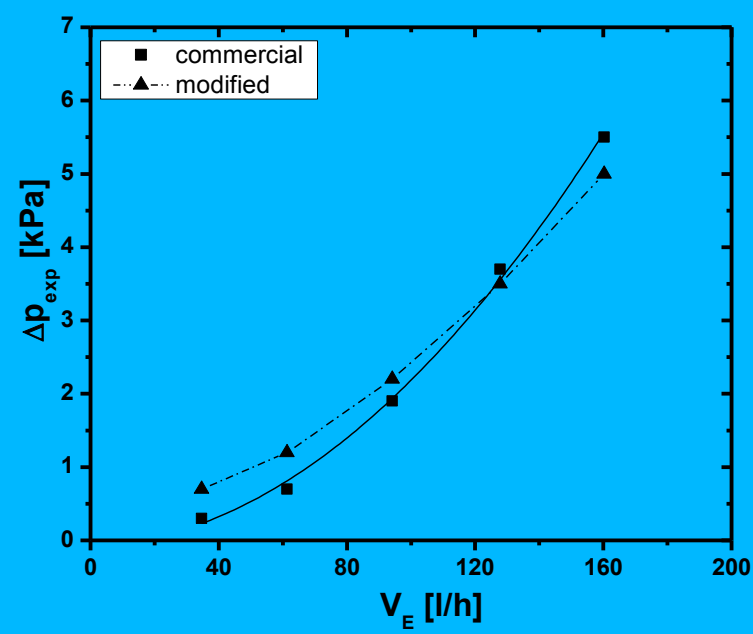

Fig. 9. Flow characteristics for ethanol

The flow characteristics show that for very low flow rates the overall pressure drop is higher for modified heat exchanger than for commercial one. However this tendency is opposite for higher values of flow rates.

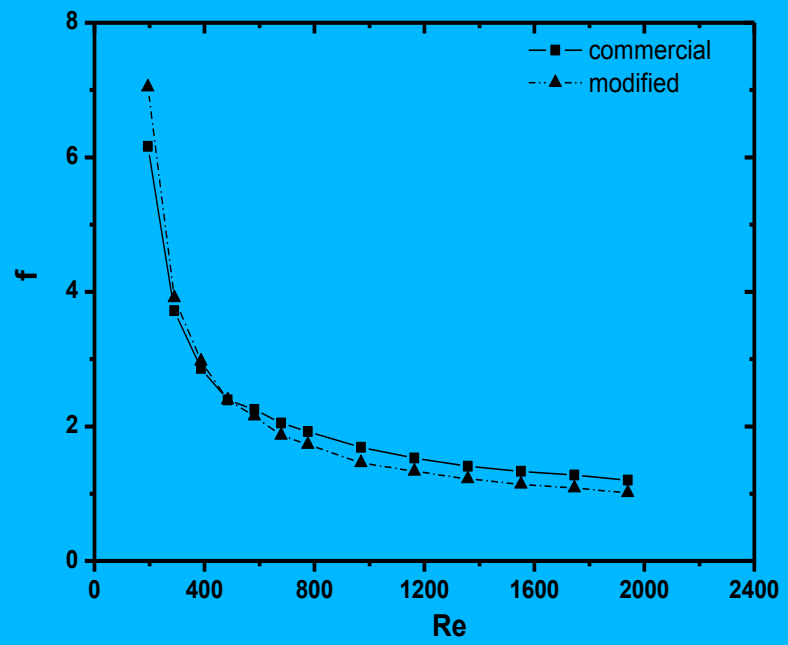

Fig. 10. Friction factor profile for water

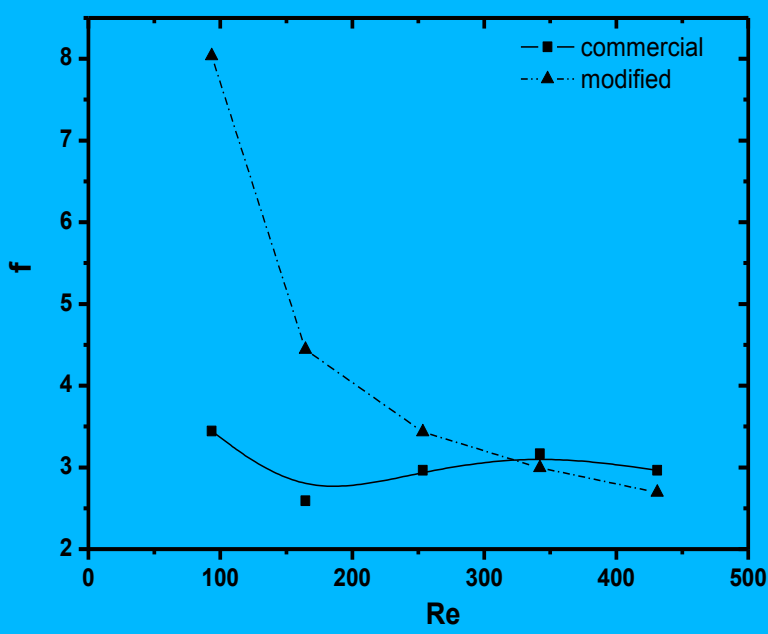

Fig. 11. Friction factor profile for ethanol

The tendency apparent in Figs. 8 and 9 corresponds to the friction factor presented as a function of Reynolds number in Fig. 10 and Fig. 11. With increasing Reynolds number the friction factor of modified surface decreased and finally became smaller than for the commercial plate.

\section{Uncertainty analysis}

An uncertainty analysis was performed to estimate errors in the experimental results. The analysis was based on the principle of propagation of uncertainties. The results of calculation are summarized in Table 1.

Table 1. Summary of the uncertainty analysis

\begin{tabular}{lc}
\hline Parameter & $\begin{array}{c}\text { Relative } \\
\text { value [\%] }\end{array}$ \\
\hline volumetric flow rate & $0.92-1.13$ \\
mass flux & $1.40-1.63$ \\
temperature & $1.00-1.15$ \\
overall heat transfer coefficient & $2.52-3.76$ \\
convective heat transfer coefficient & $3.92-5.19$ \\
pressure & $0.90-1.06$ \\
differential pressure & $1.50-1.84$ \\
friction factor & $4.91-6.23$ \\
Reynolds number & $7.30-11.45$ \\
\hline
\end{tabular}

\section{Summary}

The experimental analysis of heat transfer enhancement for plate heat exchanger was described. The results of heat transfer for the 
exchanger with modified surface were always compared with the results of the commercial one. Analysis of water-ethanol system gave very interesting data - the heat transfer coefficient on the ethanol side took higher values for the modified heat exchanger in all studied cases, but the water side it was higher for the commercial one. The first attempt to the understanding of this phenomena was undertaken. Authors considered the values of water and ethanol surface tension. The surface tension of ethanol is about four times smaller than the surface tension of water. Therefore the wettability of ethanol is larger than water and it can explain the better results of heat transfer in the case of porous layer. Analytical analysis of this phenomena is in progress.

In the flow resistance aspect, for very low flow rates the overall pressure drop is higher for modified heat exchanger than for commercial one. However this tendency is opposite for higher values of flow rates. It corresponds to the friction factor values. The explanation could be also connected with the surface tension and wetting ability of ethanol. It looks like the porous layer caused higher ethanol friction, because due to the smaller surface tension it goes "deeper" into the pores.

Presented data shows that described surface finishing is not suitable for working fluids with high values of surface tension (for example water), but can be utilized in the system, in which the working fluid has low value of surface tension (for example ethanol, refrigerants).

\section{Acknowledgements}

The investigations presented in the paper has been funded from the Strategic Research Programme SP/E/1/67484/10.

\section{References}

Arseneyeva, O., Tovazhnyansky, L., Kapustenko, P., Khavin, G., 2011. The generalized correlation for friction factor in crisscross flow channels of plate heat exchangers, Chem. Eng. Trans. 25, 399-404.
Dovic, D., Palm, B., Svaic, S., 2009. Generalized correlations for predicting heat transfer and pressure drop in plate heat exchanger channels of arbitrary geometry, Int. J. Heat Mass Tran. 52, 4553-4563.

Fernandez-Seara, J., Uhia, F.J., Sieres, J., Campo, A., 2007. A general review of the Wilson plot method and its modifications to determine convection coefficients in heat exchange devices, Applied Thermal Engineering 27, 2745-2757.

Furberg, R., Palm, B., Li S., Toprak M., Muhammed M., 2009. The Use of a Nano- and Microporous Surface Layer to Enhance Boiling in a Plate Heat Exchanger, J. Heat Transfer 131, No. 10, 101010-1-101010-8.

Gupta, M. Uniyal, 2012. Review of heat transfer augmentation through different passive intensifier methods, IOSR J. Mech. Civ. Eng. 1, 14-21.

Khan, T.S., Khan, M.S., Chyu, Ming-C., Ayub, Z.H., 2010. Experimental investigation of single phase convective heat transfer coefficient in a corrugated plate heat exchanger for multiple plate configurations. Applied Thermal Engineering 30, 1058-1065.

Müller-Steinhagen, H., 2008. Smart Surfaces for Improved Heat Exchangers, HTRI eublications,www.htrinet.com/ePubs/epubs.htm.

Shah, R.K., Sekulic, D.P., 2003. Fundamentals of heat exchange design, John Wiley and Sons Inc., New York.

Stone, K.M., 1996. Review of literature on heat transfer enhancement in compact heat exchangers, Air Conditioning and Refrigeration Center Technical Reports.

Wajs, J., Mikielewicz, D., 2014. Effect of surface roughness on thermal-hydraulic characteristics of plate heat exchanger, Key Engineering Materials 597, 63-74.

Wilson, E.E., 1915, A basis for rational design of heat transfer apparatus, Trans. ASME 37, 47-82. 